\title{
The Non-Specificity of the Duquenois-Levine Field Test for Marijuana
}

\author{
John F. Kelly ${ }^{*}$, , Krishna Addanki ${ }^{2}$ and Omar Bagasra, ${ }^{*}$, \\ ${ }^{1} 1832$ Biltmore Street NW Apt 35 Washington DC, 20009, USA \\ ${ }^{2}$ South Carolina Center for Biotechnology, Claflin University, Orangeburg, SC 29115, USA
}

\begin{abstract}
The purpose of this study is to determine the specificity, or lack thereof, of the Duquenois-Levine (D-L) field test kit in the identification of marijuana. Out of the forty-two samples tested, patchouli, spearmint, and eucalyptus tested positive for marijuana using the D-L field test. From these results, it can be concluded that the test is non-specific and can yield false positives. Therefore, it cannot be legitimately used for the prosecution or conviction of an individual for violations of the anti-marijuana laws as it does not provide proof beyond a reasonable doubt of the presence of marijuana. In fact, law enforcement personnel and the test kit manufacturer claim that the D-L field test is a specific, identification test with near perfect accuracy. In court, police officers testify falsely to the identification of marijuana in a seized substance based solely on the D-L test and other non-specific, screening tests leading to convictions. The result is the denial of the Constitutionally-guaranteed right to a fair trial, due process and countless wrongful marijuana convictions.
\end{abstract}

Keywords: Duquenois-Levine field test, False positive, Marijuana, NIK pouch test.

\section{INTRODUCTION}

There are no published studies on the specificity of the Duquenois-Levine (D-L) field test or its capacity to render false positives. Manufacturers until recently have claimed that the test does render false positives, and therefore does not identify marijuana per se. But this assertion was not based on a published study. In 1996, Captain Allan C. Rothberg of the Philadelphia Police Department reported that in 1986, he, in conjunction with the DEA and the NIK field test manufacturer, had transformed controlled substance field tests into specific identification tests. "With well over 100,000 field tests (which included cocaine and heroin tests as well as marijuana tests) done to date", he wrote, "the accuracy has never dropped under 99+\%" [1]. Rothberg provided no explanations or data to support his claim either in his unpublished report or when he was contacted by us. When we contacted the manufacturer in 2010, we were told that: "Independent testing has shown the presumptive test kits are about $99 \%$ reliable" [2]. The so-called independent testing cited by the manufacturer was Captain Rothberg's report as well as sworn affidavits and testimonies by law enforcement personnel that the (D-L) test does not render false positives. For instance, Terry Mills, while Supervisor of Drug Identification for the Georgia Bureau of Investigation, claimed to have never found a false-positive in more than 1,000 D-L tests [3]. Susan Hart Johns, while a drug analyst for the Illinois State Police, swore she found no false positives in 3-4,000 D-L tests [4]. As with Rothberg, there were no data to support these assertions.

However, it was theoretically possible that the D-L field test as opposed to the lab test was specific and did not render

*Address correspondence to these authors at the South Carolina Center for Biotechnology, Claflin University, 400 Magnolia Street, Orangeburg, SC 29115, USA; Tel: +803-535-5253; Fax: +803-535-5776;

E-mails: obagasra@claflin.edu,kjohn39679@aol.com false positives since no one had experimentally tested the field test. To address this question, we conducted the following experiments with both the D-L and KN Reagent field tests.

\section{MATERIALS AND METHODS}

In 2008, the NIK NarcoPouch 908 D-L field test kit was used to analyze numerous non-marijuana substances (including plant extracts, chocolate, medications, etc.) following the prescribed procedures by NIK which are as follows:

1. Remove clip, insert suspect material into test pack, reseal with clip and tap gently to assure material falls to the bottom of pack.

2. With the printed side of the test facing you, break ampoules from left to right. Break by squeezing the center of the ampoule with tips of thumb and forefinger.

3. Break left ampoule, agitate vigorously for at least one minute.

4. Break middle ampoule and agitate gently. A blueviolet or purple color will develop within a few seconds to a minute if marijuana is present. Allow sufficient time for the blue-violet or purple to develop, but do not allow it to become too dark.

5. As soon as the blue-violet or purple color develops, break the right ampoule. Tap the pouch once or twice and the blue-violet or purple color will be extracted into the lower layer. Upper layer color is unimportant.

6. The formation of the proper blue-violet or purple color and its extraction into the lower layer is a positive test for marijuana.

\section{RESULTS}

Patchouli, cypress, and eucalyptus tested positive for marijuana; while lavender, spearmint, oregano, and thyme gave inconclusive results. All other non-marijuana 
substances including Hershey's chocolate, over the counter medicine and a few detergents tested negative. Below are the pictures of Positive, False Positive, Inconclusive, and Negative test results. (See Fig. (1), Positive Result, False Positive Result, Inconclusive Test Result of Spearmint with D-L Test Image, Negative Test Result of Olive Oil with D-L Test Image).

\section{DISCUSSION}

The NarcoPouch 908 D-L field test kit was found to be nonspecific and subjective. The positive testing of patchouli, spearmint, and eucalyptus for marijuana demonstrates the ability of this field test kit to produce false positives. Additionally, inconsistent and inconclusive testing results of lavender, cypress, and oregano demonstrate that the results of this field test are at the discretion of the tester's color discrimination abilities. In other words, the "proper blueviolet or purple" color which yields a positive test for

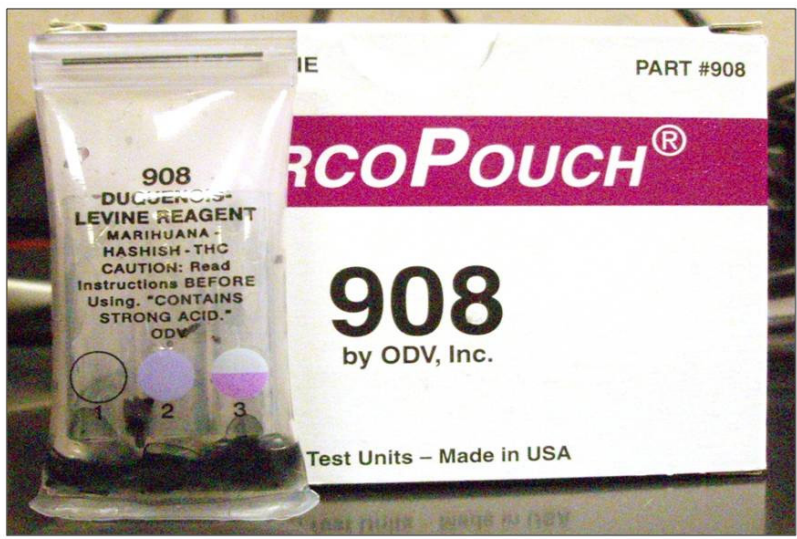

1 a) Positive Test Result of Marijuana sample with the D-L Test

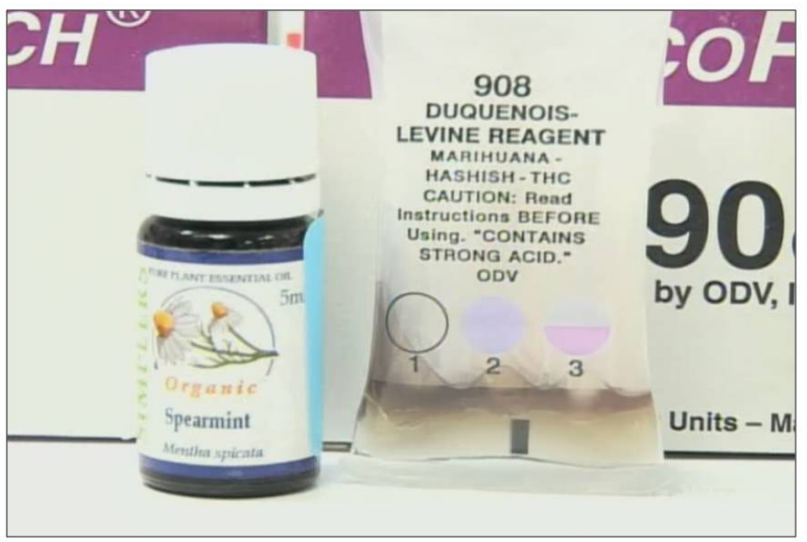

1 c) Inconclusive Test Result of Spearmint Plant Extract with the D-L Test marijuana is different for each testing official; what is blueviolet or purple enough for a positive test result to one official may not be blue-violet or purple enough for another. This means the field tests cannot be legitimately used to identify marijuana in a seized substance. The significance of this finding cannot be over emphasized particularly in light of the fact that police officers around the country now testify and "identify" the presence of marijuana in a seized substance solely on the basis of marijuana field tests such as the D-L. Since the D-L field test cannot identify the presence of marijuana, this raises the serious possibility of tens of thousands of wrongful drug convictions.

Moreover, the DEA now claims that the D-L test does not render false positives and is "error-free", according to recent testimony by DEA senior chemist Heather Hartshorn [5]. Judge J. William Ryan called her testimony "ridiculous on its face' and noted that: "Any claim of infallibility is troubling. 'Scientists, along with all other individuals,

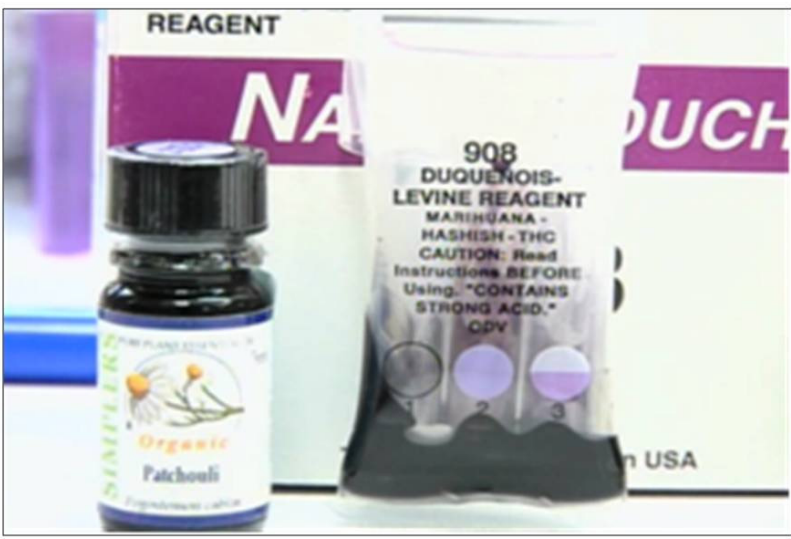

1 b) False Positive Test Result of Patchouli Plant Extract with the D-L Test

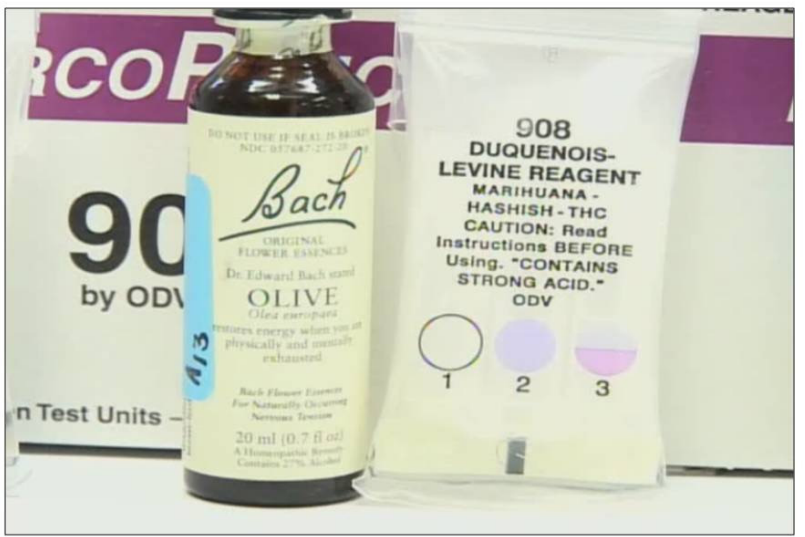

1 d) Negative Test Result with Olive Oil Plant Extract with the D-L Test

Fig. (1). (a) Positive Test Result. The image is a result obtained on testing marijuana. The formation of the proper blue-violet or purple color and its extraction into the lower layer demonstrates a positive test result for marijuana using the D-L Test. (b) The image is a result obtained on testing Patchouli Plant Extract. The formation of the proper blue-violet or purple color and its extraction into the lower layer in both cases demonstrates a positive test result for Patchouli Plant Extract using the D-L Test. (c) Inconclusive Test Result of Spearmint Plant Extract with the D-L Test. The image is a result obtained on testing Spearmint Plant Extract Two distinct layers are present; however, the color in the top layer is brownish purple and the color in the bottom layer is brown thus rendering an inconclusive test result. (d) Negative Test Result with Olive Oil. The image is a result obtained on testing Olive Oil Plant Extract The absence of a blue-violet or purple color demonstrates a negative test result for marijuana. 
evidence cognitive limitations that lead to frequent judgment error and that set surprisingly harsh restrictions on the capacity to manage complex information and to make decisions.' (David Faust. The Limits of Scientific Reasoning, 1, U. Minn. Press, 1984). Further, it is beyond cavil that such a claim of infallibility is anathema to the essence of science as understood in the last 100-plus years. Thomas Kuhn and Karl Popper, contemporary philosophers of science whose conceptions of the nature of science represent opposite-ends of the current spectrum, the former's scientific revolutionsas-paradigm-to-anomalies-to-revolution versus the latter's perpetual subjection of theory to falsifiability/testability, as well as thinkers a century-prior, all point to error as an inherent component of the scientific endeavor. (E.g., Popper, K.R., Conjectures and Refutations: The Growth of Scientific Knowledge, 116-117, Basic Books, 1963 ("[O]ur latest and best theory is always an attempt to incorporate all the falsifications ever found in the field, by explaining them in the simplest way; and this means ... in the most testable way"); Nietzsche, F.W. ("There are no facts, only interpretations") [6].

Hartshorn presented no data to support her claims of infallibility but persisted in her testimony that the D-L test in concert with two other screening tests is error-free as well as her testing. Combining screening tests does not add up to a specific identification test. Each retains its own nonspecificity and error rate, and even if each test is positive for marijuana, each one could be a false positive. Hartshorn admitted that the D-L and the other two tests in isolation rendered false positives. But when they are combined they are error free as is her testing. This is possibly perjury especially since at least two DEA studies, including one at her lab that found a $20 \%$ error rate, have reported that the D$\mathrm{L}$ test renders false positives [7] and what she claimed is scientifically impossible.

Hartshorn's unsubstantiated claims of infallibility echoed those of former and current DEA lab directors. For instance, on April 9, 1999, Joseph P. Bono, then-director of the DEA's Mid-Atlantic Laboratory and recent president of the American Academy of Forensic Sciences, submitted a sworn affidavit to the courts that all DEA analyses and tests are "incapable of producing a false positive. . In other words, even if the test results are inaccurate, the results will not indicate the presence of a controlled substance when none is present in the unknown sample. Even if the instruments used in the testing are not properly calibrated, if no controlled substance is present in the exhibit, then no controlled substance will be identified . . . even when an instrument is not functioning properly, it will not identify cocaine, or any other controlled substance, as being present in a sample, unless that controlled substance is actually present" [8].

Bono's successor at this lab, Richard Fox, was more specific in his sworn affidavit which stated, in part, that: "There is no other plant material that will give a positive result for all three tests (including the D-L and two other screening tests) ... Neither the analyst in this case, nor any other DEA analyst, has ever misidentified marijuana. . . As such, the uncertainty measurement associated with the conclusions reached by the analyst resulting in the identification of marijuana is zero" [9].
Fox's successor, James Malone, has testified, in part, as follows in a marijuana case in Washington, D.C. [10].

Prosecutor: To your knowledge, while you've been at the lab, has the laboratory ever misidentified a controlled substance?

James Malone: No.

P: Are you aware of anything which shows that a mis-calibrated system or chromatographer in this case, but any system that was not calibrated correctly would create a false positive for cocaine or a controlled substance?

JM: No.

Judge: But Mr. Chawla's position was, can it ever - can a mis-calibrated machine ever give a false positive?

JM: No. A mis-calibrated machine isn't going to give you a positive cocaine if there's not cocaine.

P: More specifically, if the reagent isn't working, is it going to show that the substance isn't marijuana? In other words, if the reagent isn't working, what's the result of the Duquenois-Levine going to be?

JM: It's going to be negative.

P: Would I get a positive out of a DuquenoisLevine test? If I used a reagent that wasn't working anymore and tried to run a Duquenois-Levine with that reagent, what would happen?

JM: You wouldn't get a false positive, no.

In short, the DEA now claims to have transformed the D$\mathrm{L}$ test from a $99+\%$ accurate test to a $100 \%$ accurate identification test that renders no false positives. Since DEA analysts claim to identify marijuana on this basis in court, this also raises the possibility of tens of thousands of wrongful marijuana convictions.

Thus, the current positions and operations of law enforcement personnel and the DEA are a serious concern and challenge to the legal and forensic science communities as they defy scientific and legal studies as well as court decisions that the D-L test alone or in combination with other tests is non-specific and does not provide constitutionally-required proof beyond a reasonable doubt of the presence of marijuana in a seized substance.

The D-L test is actually a combination of two individual tests. With the Duquenois test, a petroleum ether or chloroform extract of the plant extract is added to an ethanolic solution of vanillin and acetaldehyde, followed by the addition of concentrated hydrochloric acid. Marijuana gives a deep blue-violet color. With the Levine modification, the blue-violet test mixture obtained in the Duquenois test is shaken with chloroform. With marijuana, the blue-violet color is transferred into the chloroform layer. However, at least 50 legal substances have been shown to give the same color reactions. 
As early as 1938, the French pharmacist Pierre Duquenois, who developed the Duquenois test, found that it was not specific and gave false positives. Yet, he reported that the test was specific. Although he claimed it was specific, he worked to modify the original test into the D-L test to eliminate false positives which he was unable to do [11].

In 1975, Dr. Marc Kurzman et al., conducted a study, in collaboration with 13 other scientists, which concluded that: "The microscopic and chemical screening tests presently used in marijuana analysis are not specific even in combination for 'marijuana' defined in any way" [12]. Regarding the D-L test, Kurzman reported that: "the Levine modification test has now been proven to be simply a test for moderate weight molecular resorcinol, common plant chemical substances. The original Duquenois test was recognized in the 1960's as being highly non-specific. DeFaubert Maunder has reported finding (in a limited plant sampling) 25 plant species besides Cannabis which will give a positive Duquenois-Levine test. Smith has also found that 12 of 40 common plant oils and extracts will give a positive Duquenois-Levine test" [13].

Kurzman, who is also an attorney, proved his conclusion by winning dismissals and acquittals for his marijuana defendants on the basis that the tests were not specific and did not prove the presence of marijuana beyond a reasonable doubt [12].

The inadequacy of the D-L test has been noted by Armaki and his co-authors, "the unsatisfactory color tests Beam, Duquenois, and Chamrawy ... lack in adequate specificity..." [14]. Turk and his co-workers also reported that "the presently used colorimetric tests respond to a variety of vegetable extracts and to certain pure substances (i.e. false positives)" [15]. R.N. Smith found that 12 of 40 plant oils and extracts gave a positive D-L test [16]

M.J. de Flaubert Maunder questioned the reliability of the D-L test per se and of the 240 substances he tested, 25 tested positive for marijuana, i.e. false positives [13]. Maunder himself cautioned that the test "should never be relied upon as the only positive evidence ..." [13]. C.G. Pitt, R.W. Hemdron, and R.S. Hsia determined that the D-L test "is chemically based primarily on the presence of 1,3dioxybenzene (resorcinol) partial structure" [17]. In other words, the D-L test will be positive for many resorcinols commonly occurring plant substances and also found in common drug products. For example, Pitt found that Sucrets give a violet coloration for the test. They also tested a number of common monocyclic resorcinols and icyclic resorcinols (chromanols) and found them to give a positive D-L test. Pitt concluded that the D-L test is useful as a "screen" test but not sufficiently selective to be relied upon for "identification" [17].

Various courts have also found that the marijuana tests alone or in combination do not prove the presence of marijuana beyond a reasonable doubt. In 1973, the Supreme Court of Wisconsin ruled that "standing alone (the D$\mathrm{L} /$ microscopic exam) is not sufficient to meet the burden of proving the identity of the substance beyond a reasonable doubt" [16]. The court also pointed out that even the prosecution's expert witness, Michael Rehburg, testified "that neither of these tests was specific for marijuana. . . I It is without dispute in this record that functional group tests used by Rehburg . . . are not exclusive or specific for marijuana" [17].

In 1979, a trial judge in North Carolina blocked the conviction of C. Richard Tate by the use of the D-L test. The trial judge found that the D-L test was "not specific for marijuana" and had "no scientific acceptance as a reliable and accurate means of identifying the controlled substance marijuana" and allowed the defendant to suppress use of the test results on that basis [18]. This finding was upheld by the North Carolina Court of Appeals as well as the North Carolina Supreme Court which found that: "The determination that the test used was not scientifically acceptable because it was not specific for marijuana was amply supported by the facts. . . The trial court's ruling that the results of the tests conducted on green vegetable matter by using the Duquenois-Levine color test in the Sirchie drug kit were inadmissible in evidence was supported by the court's findings that the test is not scientifically accepted, reliable or accurate and that the test is not specific for marijuana because it reportedly also gives a positive reaction for some brands of coffee and aspirin. . . . The conclusion to exclude the test results is amply supported by these findings of fact . . . and the test results were properly suppressed ..." [19].

In 1979, the U. S. Supreme Court, in Jackson v. Virginia, found, in effect, that non-specific drug tests that render false positives such as the D-L, cannot prove the presence of marijuana, and therefore cannot be the basis for prosecution, let alone conviction [20].

\section{CONCLUSION}

The devastating effect of admitting conclusory reports and the results of nonspecific drug tests such as the D-L test as evidence has been eloquently enunciated by Professor Edward Imwinkelried [21]. He wrote: "It is not only unnecessary for the courts to accept conclusory drug identifications based on nonspecific tests, it is also unwise for them to do so. The essence of the scientific method is formulating hypotheses and conducting experiments to verify or disprove the hypotheses. A proposition does not become a scientific fact merely because someone with impressive academic credentials asserts it is a fact. Testimony should not be treated as an expert, scientific opinion without a truly scientific basis, such as experimentation. Conclusory drug identification testimony is antithetical and offensive to the scientific tradition, and courts should not allow ipse dixit to masquerade as scientific testimony.

“. . . It would eviscerate the Jackson standard to sustain conclusory drug identification in the teeth of the judicially noticeable fact that every test used to identify the substance is nonspecific. Even more importantly, sustaining such drug identifications places a judicial imprimatur on testimony that cannot justifiably be labeled scientific. The rejection of such identifications is necessitated not only by due process but also by the simple demands of intellectual honesty. After Jackson, sustaining conclusory, nonspecific drug identification evidence is both bad science and bad law" [21]. 


\section{ACKNOWLEDGEMENTS}

Research support was provided by the Investigative Fund from The Nation Institute (JK) and a grant from National Institute of Justice (OB). We would like to acknowledge the inspiration of Dr. Frederic Whitehurst.

\section{CONFLICT OF INTEREST}

Declared none.

\section{REFERENCES}

[1] Allan, C.R. Narcotic Field Tests: A case study in successful implementation. Unpublished report, 1995.

[2] Personal communication from T. Allen Miller Products Manager, Forensics Investigation \& Examination for Safariland 13386 International Parkway Jacksonville, FL 32218 July 14, 2010.

[3] The People of the State of New York v Juan Escalera, Criminal Court of the City of New York, County of New York, 143 Misc. 2d 779; 541 N.Y.S. 2d 707; 1989, Memorandum in Support of Conversion of Complaint to Information, Judge Michael A. Gary, April 25, 1989 Affidavit, Terry Mills, Georgia Bureau of Identification, April 11, 1989.

[4] Ibid., Affidavit, Susan Hart Johns, Bureau of Forensic Science/Illinois State Police, April 11, 1989.

[5] In Re O.W. D.C. Superior Court/Family Court, 09-DEL 1997, April 2,2010

[6] Ibid.

[7] Hughes, R.; Warner, V. A study of "false positives" in the chemical identification of marihuana -drug enforcement administration laboratory notes. Microgram, Vol. IX, No. 7, July, 1976.

[8] Declaration of Joseph P. Bono, Lab Director/DEA Mid-Atlantic Laboratory, Washington, D.C. April 9,1999, pp. 3-4.
[9] Affidavit of Richard Fox, Lab Director/DEA Mid-Atlantic Laboratory, June 7, 2006, Washington, D.C., p. 1.

[10] USA v. Darryl M. Williams and Kevin Ross, D.C. Super. Ct. Crim. Nos.2010 CMD 3630 and 2010 CMD 3631, Sept. 17, 2010, Tr. pp. $59,60,72$.

[11] Duquenois, P.; Moustaha, H.N. Identification and Assay of Cannabis Indicia. J. Egypt. Med. Assoc., 1938, 21, 21

[12] Kurzman, M.; Fullerton, D. with contributions by Michael O. McGuire, Winning Strategies for Defense of Marijuana Cases: Chemical and Biological Issues, J. Chem. Def., 1975, 1, 487.

[13] De Faubert Maunder, M.J. Two simple colour tests for Cannabis, UNODC Bulletin on Narcotics, Issue 4 - 005, (1969), 37-42.

[14] Aramaki, H.; Tomiyasu, N.; Yoshimura, H.; Tsukamoto, H. Forensic chemical study on Marijuana. Chem. Phar. Bull. Japan, 1968, 16,822 .

[15] Turk, R.F.; Dharir, H.; Forney, A. A simple chemical method to identify Marijuana. J. Forensic Sci., 1969, 14, 389.

[16] Smith, R.N. A Brief Note on the Response of Some essential Oils and Extracts to the Duquenois-Levine Test. J. Forensic Sci., 1974, 14, 191.

[17] Pitt, C.G.; Hemdron, R.W.; Hsia, R.S. The specificity of the duquenois color test for Marijuana and Hashish. J. Forensic Sci., 1972, 17(4), 693-700.

[18] State v. Wind, 60 Wis. 2d 267 (Supreme Court of Wisconsin, 1973) 208 N.W. 2d 357. See also City of Eagan v. Mittlesdorf, Dakota County Court, Minnesota (1974) file f/4-1-8556; State v. Byers, (Municipal Court, Minneapolis, Minnesota, 1974) case \#1371173; and State of Missouri v. Richard Gilmore, Missouri 3d Circuit District Court, October 9, 1974.

[19] State of North Carolina v. C. Richard Tate, 300180 N.C. S.E. $2 d$ (1980)

[20] Jackson v. Virginia 443 U.S. 307 (1979).

[21] Imwinkelried, E.J. Jackson v. Virginia: Reopening the pandora's box of the legal sufficiency of drug identification evidence. $K Y$ Law J., 1984, 76(1), 11-12. 